\section{Screening for breast health}

\section{MARGARET REICH \\ Senior Staff Editor}

January may be more than half over, but it's still not too late to make-and keep-a New Year's resolution. For women, that should be to take better care of their breasts. This proves particularly important considering that about one in 10 women will develop breast cancer during her life.

A woman doesn't have to be part of those statistics, however. Breast self-examination (BSE), physician examination, and mammography comprise a structured approach to maintaining breast health. Used alone, each one features certain limitations, but together they can help reduce the mortality of breast cancer through early detection.

Before discussing each of these screening methods, a mini-lesson in breast anatomy seems appropriate.

\section{Knowing the breasts}

Beginning at the chest wall, the rib, pectoralis minor muscle, and pectoralis major muscle serve as the "foundation" for each breast. Both pectoral muscles extend into the armpit (axillary) area. Lymph nodes are found here. They act as a filter for bacteria or other undesirable agents retrieved from the lymph system. Lymph is a transparent liquid that circulates throughout the body, providing protection against disease.

Divided into lobes, the breast interior also features lobules with milk-secreting glands. These are cushioned by fat in addition to the pectoral muscles. Milk produced from these glands is distributed via tiny ducts to a holding chamber of sorts, called the ampulla. The nipple, made of erectile tissue, is located just above this holding chamber. It varies in color from a light pink to almost black in some women. At the base of the nipple are Montgomery's glands. They produce oil and maintain nipple suppleness.

On the outside, the areola surrounds the nipple. In some women, hair may be found here. Generally, the nipple protrudes beyond the areola. However, some women may have a naturally inverted nipple. While this does not signal trouble, any changes that may occur in the nipple or elsewhere should be brought to a doctor's attention.

Just as breasts may vary slightly in size, shape, and color among women, so does the texture. Some breasts are lumpy in nature. Lumps do not always signal the presence of cancer. Fluid-filled tissue sacs (cysts) can produce lumps, as well. Likewise, lumps can be due to noncancerous (benign) tumors. The most common of these are called fibroadenomas. Made up of fibrous and glandular tissue, fibroadenomas feel round although somewhat rubbery. They frequently occur in the nipple area or near the upper breast sides. Unlike other lumps, fibroadenomas usually don't feel tender and they are frequently small in size.

Infection can ensue in nursing women. Sometimes nipples crack allowing undesirable agents to enter the breast. Swelling, redness, and pain may occur. In more severe cases, tissue surrounding the affected area may harden in an attempt to protect against infectious spread. The hardened area may be full of pus. This is known as an abscess. However, in nonnursing women, any of the aforementioned symptoms may signal the possible presence of cancer.

\section{The importance of BSE}

Certainly, any of these conditions warrant a physician's attention. Yet, unless a woman regularly examines her breasts, chances are she won't know what, if any, lumps are present. Nor will she recognize when a lump that previously did not exist, 
emerges. For this reason, the American Cancer Society (ACS) recommends women over age 20 perform monthly BSE.

Yet, nearly two-thirds of American women do not perform BSE. Reasons for noncompliance vary. Some of the more common ones include fear of discovering cancer; "The-I'm-no-expert, so-how-do-l-know-whatI'm-feeling" excuse; and fear that it may be too late to do anything at the stage a lump is discovered.

Overcoming cancer phobia is not easy. But the facts are BSE helps save lifes. The earlier cancer is detected and treated, the better the chances of survival. One study found that the 5 -year survival rate was $75 \%$ for women who regularly practiced BSE. Those who did not perform this monthly procedure had a $57 \%$ survival rate over the same time.

Likewise, who better to know her breasts than the woman herself? Of course, a physician is the medical expert, but the woman has the opportunity to know every nuance of her breasts. That's hardly possible for a physician who may examine a patient once or twice a year. Therefore, it's not surprising that about $80 \%$ of lumps are discovered by women themselves.

The trick is to perform BSE correctly and at the right time of the month. Although the illustration on page 115 shows the steps involved, a few extra points need mentioning:

- Breasts should be examined at about the same time each month. Due to hormonal changes that occur during a woman's menstrual cycle, it's best to perform BSE about 3 to 7 days after the period ends. At this time the breasts are less engorged and tumors can be found more readily. Postmenopausal women should pick one day out of the month to perform BSE and do so consistently.

- The entire breast, including the armpit area where the lymph nodes are located, needs to be palpated. For some women, performing the actual palpatory technique in the shower may enhance the ability to detect out-of-the-ordinary lumps.

- The same pattern of examination should be practiced every month. While three methods are illustrated on page 115 , other methods may be used.* A woman should choose a technique she's most comfortable with and one that provides the greatest coverage. A physician or heathcare professional can suggest a suitable method based on the individual.

- Using the middle fingers (from the tips to the first joint), enough pressure should be applied to feel deep breast tissue.

- Any lumps that may be detected should be noted. Some physicians give their patients a drawing of the breasts on which the location of any lumps can be marked. Keeping a record helps a woman familiarize herself with her normal breast texture. She can tell if any lump may have gotten smaller or bigger or appeared where one did not exist the month before. These changes call for a patientdoctor discussion.

- A physician or heathcare provider will teach a woman BSE techniques. Local chapters of the ACS offer information on the subject, as well. The more frequently BSE is done, the more confident a woman will be in her ability to perform it correctly.

By itself, BSE proves less accurate in detecting lumps than mammography and physician examination combined. However, it does serve as the first method of breast cancer detection.

Notes Roger Fenton, DO, director of the Women's Breast Centers (Southfield, Mich), and chairman of the department of radiology and medical imaging at Huron Valley Hosptial (Milford, Mich), "Because it is cheap and can be done readily and easily, we can only gain positive information from BSE. But we can't depend on it exclusively. We need to

\footnotetext{
* The MammaCare ${ }^{\notin}$ approach uses a grid or vertical examination pattern in which the woman applies three varying degrees of pressure to each palpated area. The technique allows women to feel lumps as small as $4 \mathrm{~mm}$. A model simulating the female breast helps women distinguish between ordinary nodules and lumps, and suspicious ones. An at-home kit and follow-up training comprise the program as well. Currently, the program is available to patients only through their physicians. Medical personnel may contact Mammatech Corp, $930 \mathrm{NW}$ 8th Ave, Gainesville, FL 32601, (800) 626-2273.
} 


\section{How to perform breast self-examination (BSE)*}

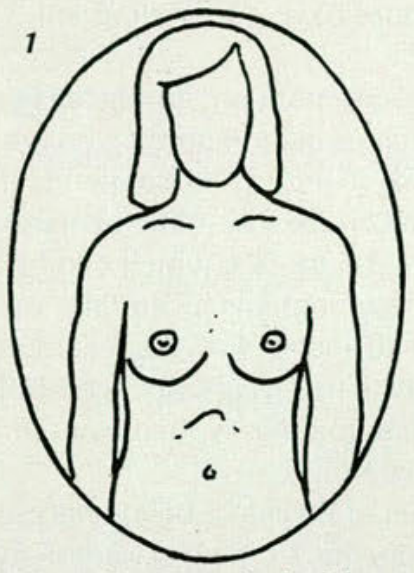

Looking in a mirror, examine both breasts for any puckering, dimpling, or scaly skin. Watch for any nipple discharge.

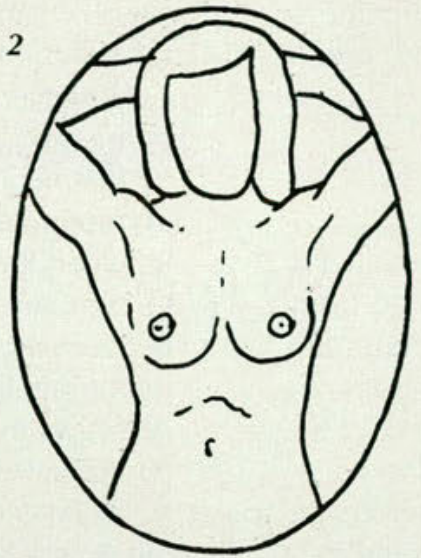

Clasp hands behind head and press forward. Any changes in breast shape or contour should be noticed at this time.

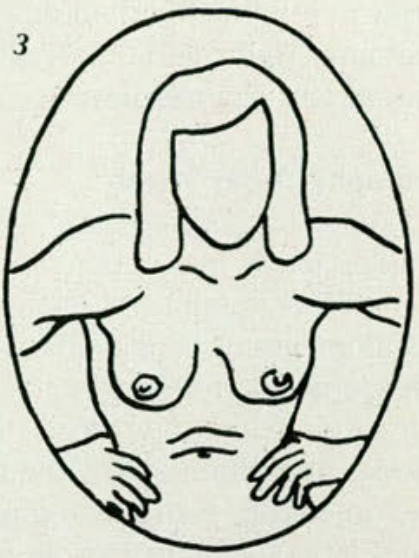

Bow slightly toward the mirror with hands on hips. Pull shoulders and elbows forward. Once again, watch for any difference in breast contour.
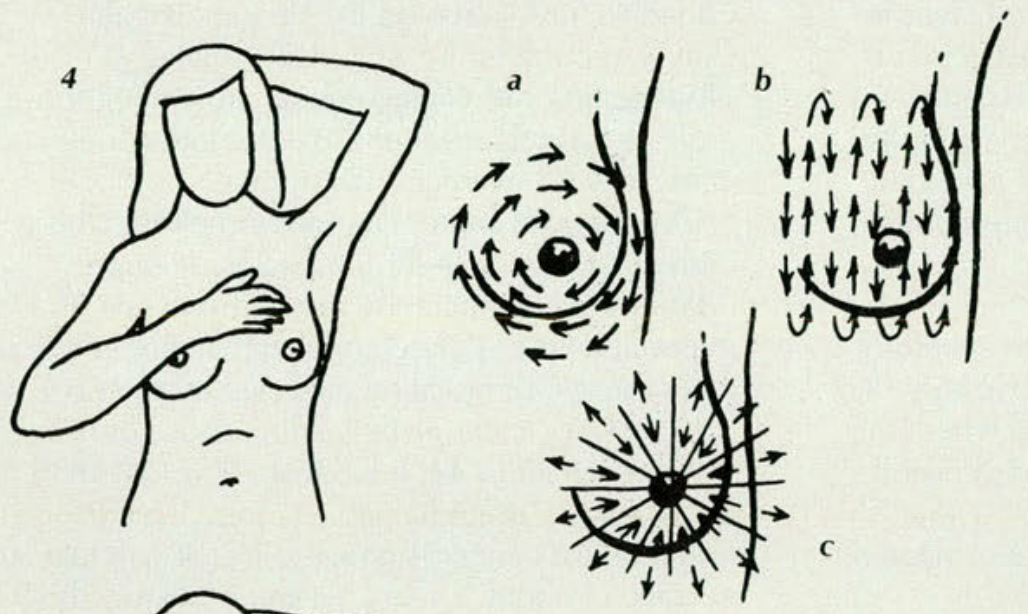

Raise the left arm. Using the three middle fingers from your right hand - tip to first joint only-carefully palpate the entire breast area. Start at the outer edges, pressing in a circular motion. The circular technique (figure a) uses a spiral pattern. Breasts can be felt in a grid-like fashion (figure b) or spoke-like manner. Remember to palpate the armpit and its surrounding area. Likewise, examine the nipple.
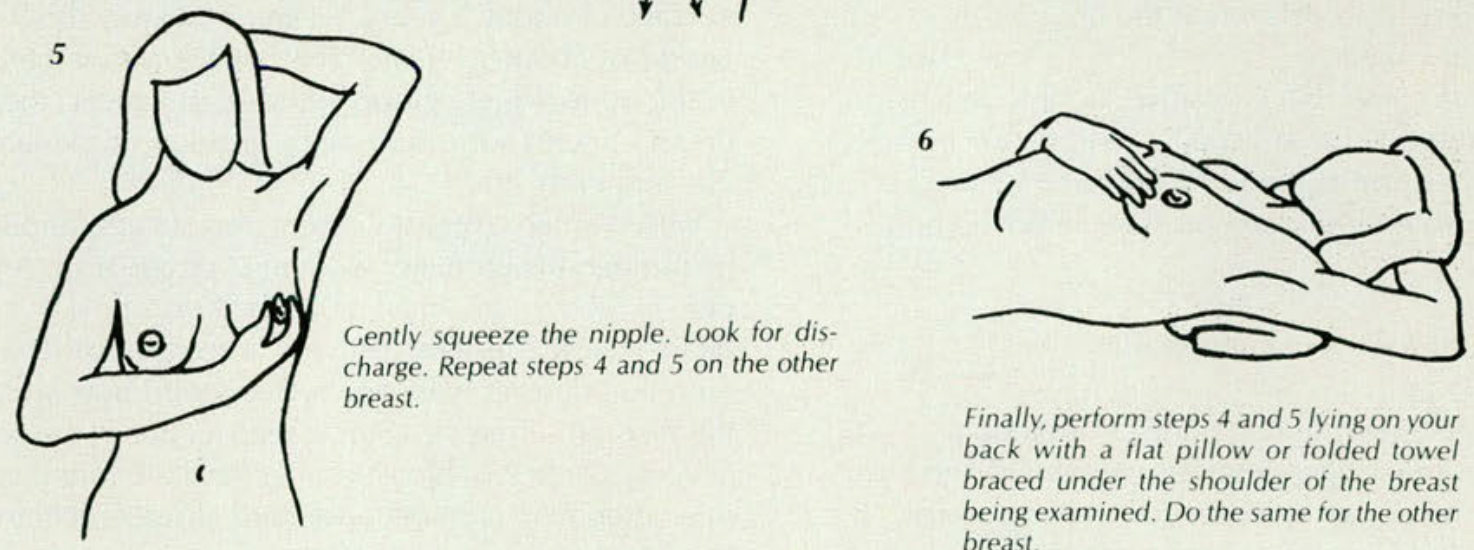

Finally, perform steps 4 and 5 lying on your back with a flat pillow or folded towel braced under the shoulder of the breast being examined. Do the same for the other breast. 
incorporate it in a structured approach that includes mammography, dedicated breast ultrasound, and (physician) breast examination."

\section{Mammography: X-ray vision}

In the simplest terms, mammography is a specialized breast $\mathrm{x}$-ray. The amount of radiation emitted from today's mammograms is negligible. Mammography can detect tumors before they can be felt. Early detection may prevent the spread of cancer to the lymph nodes and other nearby organs.

On the downside, mammography doesn't locate all cancers. About $10 \%$ to $15 \%$ go undetected in part because this $\mathrm{x}$-ray has trouble delineating tumors or lumps in dense breasts. Younger women's breasts are naturally more dense than are older women's. Likewise, mammography may not offer as clear a picture in women who have silicone breast implants. In such instances, Dr. Fenton recommends dedicated breast ultrasound as a supplement to mammography. In dedicated breast ultrasound, high-frequency sound waves reveal internal structures of the suspicious tumor or lump.

Ultrasound is not as accurate in detecting abnormalities as mammography. However, before cancer can be diagnosed, a biopsy is necessary. It may be performed in a physician's office where the breast might be anesthesized locally. In skinny needle biopsy, a needle, injected into the breast, extracts cells from the suspicious area. These are evaluated by a pathologist to determine the absence or presence of cancer.

If the test comes back positive, a more extensive biopsy, performed in a hospital, will be necessary. Usually, that means the lump and a small area of normal surrounding tissue must be removed and analyzed.

\section{Who should have a mammogram?}

The medical community endorses an annual mammogram for asymptomatic women 50 and over who may be at risk for breast cancer. Some risk factors include: previous breast cancer (especially at a young age); family history of premenopausal breast cancer; obesity; and first-time motherhood after age 35 . Of course, any woman who may show signs of cancer should have a mammogram, regardless of age.

However, agreement ends concerning the benefits of mammography for younger women who may not be deemed high risk. The ACS recommends that asymptomatic women have a baseline mammogram between the ages of 35 and 39, which can be used to compare with mammograms taken later in life. Between the ages of 40 and 49 , the ACS recommends mammograms every 1 to 2 years. By age 50 , the ACS says every asymptomatic woman should have an annual mammogram.

These general guidelines have been endorsed by the American Osteopathic College of Radiology, the American College of Radiology, and the American Medical Association. However, the National Cancer Institute, the American College of Physicians, the Canadian Task Force on the Periodic Health Examination, and the American College of Obstericians and Gynecologists are among those professional organizations that do not endorse such guidelines for average-risk women.

On the other hand, Dr. Fenton believes these current ACS guidelines don't go far enough:

"Baseline mammography at or around age 30 is important. First, it's been proven that the breasts are less sensitive to radiation after age 30 than before. Also, breast cancer is the leading cause of death in women age 40 to 44 . It takes about 6 to 8 years for breast cancer to be palpable (about $1 \mathrm{~cm}$ in size). If that breast cancer is going to kill, it will take an average of about 5 years. So we're talking about a period of about 13 years. That means for women in the 40 to 44 age group with breast cancer, these breast cancers were starting to develop in the late 20 s and early 30s."

The Women's Breast Centers also suggest annual mammograms for every woman over age 40. "Any person who is a woman and age 35 is at risk for breast cancer. The term 'high risk' is really a statistical term that doesn't have much to do with how we at the Women's Breast Centers screen for breast cancer. Seventy percent of breast cancers that are found are in women who are not considered at risk," declares Dr. Fenton.

Such a lack of consensus concerning general guidelines may explain in part why less than $50 \%$ of women, age 40 to 49 , have had a mammogram. 
Whether or not mammography is appropriate can only be determined on an individual basis. The physician can educate the patient regarding the pluses and minuses of the procedure, but ultimately, the woman must make the final choice.

\section{Before mammography ...}

Should a woman decide to have a mammogram, she should not hesitate to ask the following questions beforehand:

- Is the $\mathrm{x}$-ray technologist trained in using mammography?

- Does the facility use dedicated mammogram equipment? In other words, is the equipment used expressly for mammograms?

- How often is the equipment inspected and tested? It should be done annually.

- Is the radiologist (the physician who interprets the results) board certified? He or she should be trained in performing mammography.

\section{What to expect}

While mammograms can be taken any time during the month, women who menstruate may want to wait about a week after the period ends before having a mammogram for the same reasons BSE should be performed in the first half of the menstrual cycle.

The procedure is usually performed with the patient standing. The breast is positioned on a plate above an x-ray film. Breasts are compressed with a paddle. This evens out the breast tissue for an easier view of internal structures. Slight discomfort may occur during the compression.

The actual mammogram takes only a few minutes. Results are back within a few days. Average cost ranges anywhere from $\$ 40-\$ 100$. Most insurance companies don't cover the cost if the mammogram is used for screening purposes. In January 1990, Medicare will cover at least part of the cost for women over age 65.

\section{The results}

Mammograms that indicate the presence of a tumor should be confirmed with a biopsy. About $80 \%$ of tumors are benign. And, while a positive result is apt to frighten anyone, it doesn't automatically mean the loss of a breast. Sometimes only the tumor and surrounding tissue are removed followed by radiation with chemotherapy. If the lymph nodes are involved, treatment tends to be more drastic as in radical mastectomy where the breast and lymph nodes are removed. In cancers that have not metastasized or spread to other areas of the body, survival rates are more than $90 \%$. When a lymph nodes are affected, survival rates drop to about $53 \%$.

These figures are likely to stay the same unless more women, together with their physicians, advocate and participate in breast cancer screening.

"Annual mammmography is something women owe themselves. The old concept that a woman would go to her doctor for breast examination, and he would send her to a radiologist for a mammogram if something was felt, is not valid anymore.

"Breast cancer is epidemic in this country. We can no longer afford a casual approach to it," declares Dr. Fenton.

(All material in the Patient Health Guide is reviewed by IAOA physician referees.)

\section{References}

Breast cancer. Cancer facts \& figures-1987. American Cancer Society, New York, 1987.

Breast cancer: Screening and diagnosis in a primary care practice. By Blake Cady. Primary Care \& Cancer, vol 6, pp 28-37, Apr 86.

Breast self-examination (letter). By Roger S. Foster, Ir. The fournal of the American Medical Association, vol 258, pp 1332-1333, Sept 11, 1987.

Breast self-examination and survival from breast cancer. By Charles $M$. Huguley, Ir., Robert L. Brown, Raymond S. Greenberg, et al. Cancer, vol 62, pp 1389-1396, Oct 1, 1986

Breast self-examination in young women: More harm than good? By I.W. Frank and V. Mai. The Lancet, vol II, pp 654-657, Sept 21, 1985.

The Columbia University College of Physicians and Surgeons Complete Home Medical Guide. Edited by Donald F. Tapley, et al. Crown Publishers, Inc, New York, 1985.

Early detection of breast cancer: Guidelines for teaching breast self- 
examination. By Joyce Hausdorff. Primary Care \& Cancer, vol 8, pp 33-35, Jan 1988

How to beat breast cancer. By Joanne Silberner. U.S. News \& World Report, pp 52-61, July 11, 1988

Is mammography painful? By Paul C. Stomper, Daniel B. Kopans, Norman L. Sadowsky, et al. Archives of Internal Medicine, vol 148, pp 521-524, March 1988.

MammaCare: An overview (press kit). Mammatech Corporation, Gainesville, Fla, 1988.

Mammography and breast implants. By Harry Hayes, Ir., James Vandergrift, and Wilma C. Diner. Plastic and Reconstructive Surgery, vol 82, pp 1-6, July 1988

Mammography before age 50 years? (editorial). By John C. Bailar III. The Journal of the American Medical Association, vol 259, pp 1548-1549, March 11,1988

Mixed messages on mammograms. By Michael P. Harris. Time, vol 131 pp 70-71, March 28, 1988.
A practical approach to breast cancer screening and diagnosis. By Edwin B. Cox. The Female Patient, vol 11, pp 60-68, June 1986.

Special touch: A personal plan of action for breast health (pamphlet). The American Cancer Society, New York, 1987

A step-by-step guide to breast self-examination (poster). Primary Care \& Cancer, vol 6, Apr 1986

A study of women's awareness and use of mammograms. Sponsored by the American Cancer Society. The Journal of the Kentucky Medical Association, vol 85, pp 553-555, Sept 1987.

Why women don't get mammograms (and why they should). By Judith Willis. FDA Consumer, vol 21, pp 5-7, May 1987.

Women should not be lulled by mammograms that show no abnormalities (Personal Health). By Jane E. Brody. The New York Times, Sept 22, 1988.

The value of mammography screening in women under age 50 years. By David M. Eddy and William McGivney. The Journal of the American Medical Association, vol 259, pp 1512-1519, March 11, 1988. 
A NEW H Antagonist

Effective once-nightly

duodenal ulcer therapy available in a

Unique Convenience Pak

for better patient compliance

\section{AXID}

Brief Summary. Consult the package insert for preseribing information.

Indications and Usage: Axid is indicated for up to eight weeks for the treatment

of active duodenal ulcer. in most patients, the uicer will heal within four weeks.

a reduced dosage of $150 \mathrm{mg} \mathrm{h}$.s. after healing of an active duodenal ulcer.

The consequences of continuous therapy with Axid for longer than one year

are not known

Contraindication: Axid is contraindicated in patients with known hypersensitivity

to the drug and should be used with caution in patients with hypersensitivity to

other $\mathrm{H}_{2}-$ receptor antagonists.

Precautions: General -1 . Symptomatic response to nizatidine therapy does not preclude the presence of gastric malignanc,

2. Because nizatidine is excreted primarily by the kidney, dosage should be educed in patients with moderate to severe renal insufficienoy

3. Pharmacokinetic studies in patients with hepatorenal syndrome have not with normal renal function and uncomplicated hepatic dysfunction, the disposition of nizatidine is similar to that in normal subjects. occur during therapy with nizatidine.

Drug Interactions - No interactions have been observed between Axid and theophylline, chlordiazepoxide, lorazepam, lidocaine, phenytoin, and wartarin. system; therefore, drug interactions mediated by inhibition of hepatic metabolism are not expected to occur. In patients given very high doses (3.900 $\mathrm{mg}$ of aspirin daily, increases in serum salicylate levels were seen when Carcinogenesis, Mutagenesis, Impairment of fertiilty - A two-year oral carcinogenicity study in rats with doses as high as $500 \mathrm{mg} / \mathrm{kg} / \mathrm{day}$ (about 80 carcinogenic effect. There was a dose related increase in the density of enterochromaffin-like (ECL) cells in the gastric oxyntic mucosa. In a two-year study in mice, there was no evidence of a carcinogenic effect in male mice: although hyperplastic nodules of the liver were increased in the high dose males bout 330 times the human dose) showed marginally statistically significant increases in hepatic carcinoma and hepatic nodular hyperplasia with no carcinoma in the high dose animals was within the historical control limits seen or the strain of mice used. The female mice were given a dose larger than the compared to concurrent controls, and evidence of mild iver injury (transaminase given an excessive, and somewhat hepatotoxic dose, with no evidence of a carcinogenic effect in rats, male mice, and fermale mice (given up to $360 \mathrm{mg} / \mathrm{kg}$ ) day. about 60 times the human dose), and a negative mutagenicity battery is not considered evidence of a carcinogenic potential for Axid.

Axid was not mutagenic in a battery of tests performed to evaluate its potential genetic toxicity, including bacterial mutation tests, unscheduled DNA synthesis. sister chromatid exchange, and the mouse lymphoma assay. In a two-generation, perinatal and postnatal, fertility study in rats, doses of
nizatidine up to $650 \mathrm{mg} / \mathrm{kg} / \mathrm{dar}$ produced no adverse effects on the reproductive

Pregnancy-Teratogenic Effects - Pregnancy Category $C$-Oral reproduction studies in rats at doses up to 300 times the human dose, and in Dutch Belted tertility or teratogenic effect; but, at a dose equivalent to 300 times the human dose, treated rabbits had abortions, decreased number of live fetuses, and depressed fetal weights. On intravenous administration to pregnant New Zealaning White rabbits, nizatidine at $20 \mathrm{mg} / \mathrm{kg}$ produced cardiac enlargement, coarctation of the aortic arch, and cutaneous edema in one fetus and at $50 \mathrm{mg} / \mathrm{kg}$ it produced
ventricular anomaly, distended abdomen, spina bifida, hydrocephaly, and enlarged heart in one fetus. There are, however, no adequate and well-controlled studies in pregnant women. It is also not known whether nizatidine can cause tetap acirm. Wizatidine should be used during pregnancy only it the potential benefit capacity. Nizatidine should be used durifies the potential risk to the tetus.

Nursing Mothers - Nizatidine is secreted and concentrated in the milk of lactating rats. Pups reared by treated lactating rats had depressed growth rates. Although no studies have been conducted in lactating women, nizatidine is assumed to be secreted in human milk, and caution should be exercised when nizatidine is administered to nursing mothers.

Pediatric Use - Satety and effectiveness in children have not been established. Use in Elderly Patients - Uicer healing rates in elderly patients are similar to those in younger age groups. The incidence rates of adverse events and laboratory test abnormainties are also similar to those seen in other age groups.
Age alone may not be an important factor in the disposition of nizatidine. Elderly Age alone may not be an important factor in

Adverse Reactions: Clinical trials of nizatidine included almost 5,000 patients given nizatidine in studies of varying durations. Domestic placebo-controlled trials included over 1,900 patients given nizatidine and over 1,300 given placebo trials, sweating $(1 \%$ vs $0.2 \%$ ). urticaria $(0.5 \%$ vs $<0.01 \%)$, and somnolence $(2.4 \%$ vs $1.3 \%$ ) were significantly more common in the nizatidine group. variety of less common events was also reported; it was not possible to Axid* (nizatidine, Lilly)

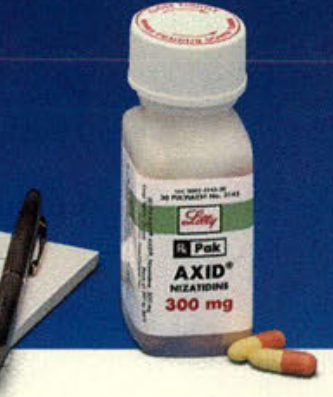

determine whether these were caused by nizatidine.
Hepatic- Hepatocellular injury, evidenced by elevated liver enzyme tests (SGOT [AST], SGPT [ALT], or alkaline phosphatase), occurred in some patients possibly or probably related to nizatidine. In some cases, there was marked elevation of SGOT, SGPT enzymes (greater than 500 IU/L), and in a single instance. SGPT was greater than 2,000 IU/2. The overall rate of occurrences of elevated liver enzymes and elevations to three times the upper limit of normal, however, did not significantly ditter from the rate of liver enzyme abnormalities in of Axid.

Cardiovascular-In clinical pharmacology studies, short episodes of asymptomatic ventricular tachycardia occurred in two individuals administered in three untreated subjects. Endocrine - Clinical pharmacology studies and controlled clinical trials decreased libido were reported with equal frequency by patients whe received Axid and by those given placebo. Rare reports of gynecomastia occurred. Hematologic - Fatal thrombocytopenia was reported in a patient who was treated with Axid and another $\mathrm{H}_{2}$-receptor antagonist. On previous occasions. this patient had experienced thrombocytopenia while taking other drugs.
Integumenta/ - Sweating and urticaria were reported significantly more Integumental-Sweating and urticaria were reported significantly more
trequently in nizatidine than in placebo patients. Rash and extoliative dermattis were also reported.

Oiner-Hyperuricemia unassociated with gout or nephrolithiasis was

Overdosage: There is little clinical experience with overdosage of Axid in humans. If overdosage occurs, use of activated charcoal, emesis, or lavage should be considered along with clinical monitoring and supportive therapy.
Renal dialysis for four to six hours increased plasma clearance by approximately $84 \%$. type effects, including lacrimation, salivation, emesis, miosis, and diarrmea. Single oral doses of $800 \mathrm{mg} / \mathrm{kg}$ in dogs and of $1.200 \mathrm{mg} / \mathrm{kg}$ in monkeys were not lethal. Intravenous $L_{\text {so }}$ values in the rat and mouse were $301 \mathrm{mg} / \mathrm{kg}$ and 232 $\mathrm{mg} / \mathrm{kg}$ respectively. PV 2091 AMP [041288]

Axids (nizatidine, Lilly)

Eli Lilly and Company

Liely Indianapolis, Indiana

NZ-2901-T-849340 O 1988, FULULYAND COMPANY 


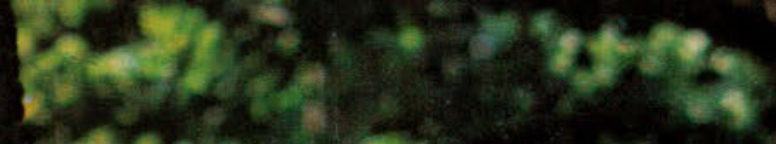

The quality
of trust.

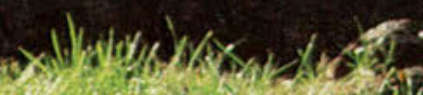

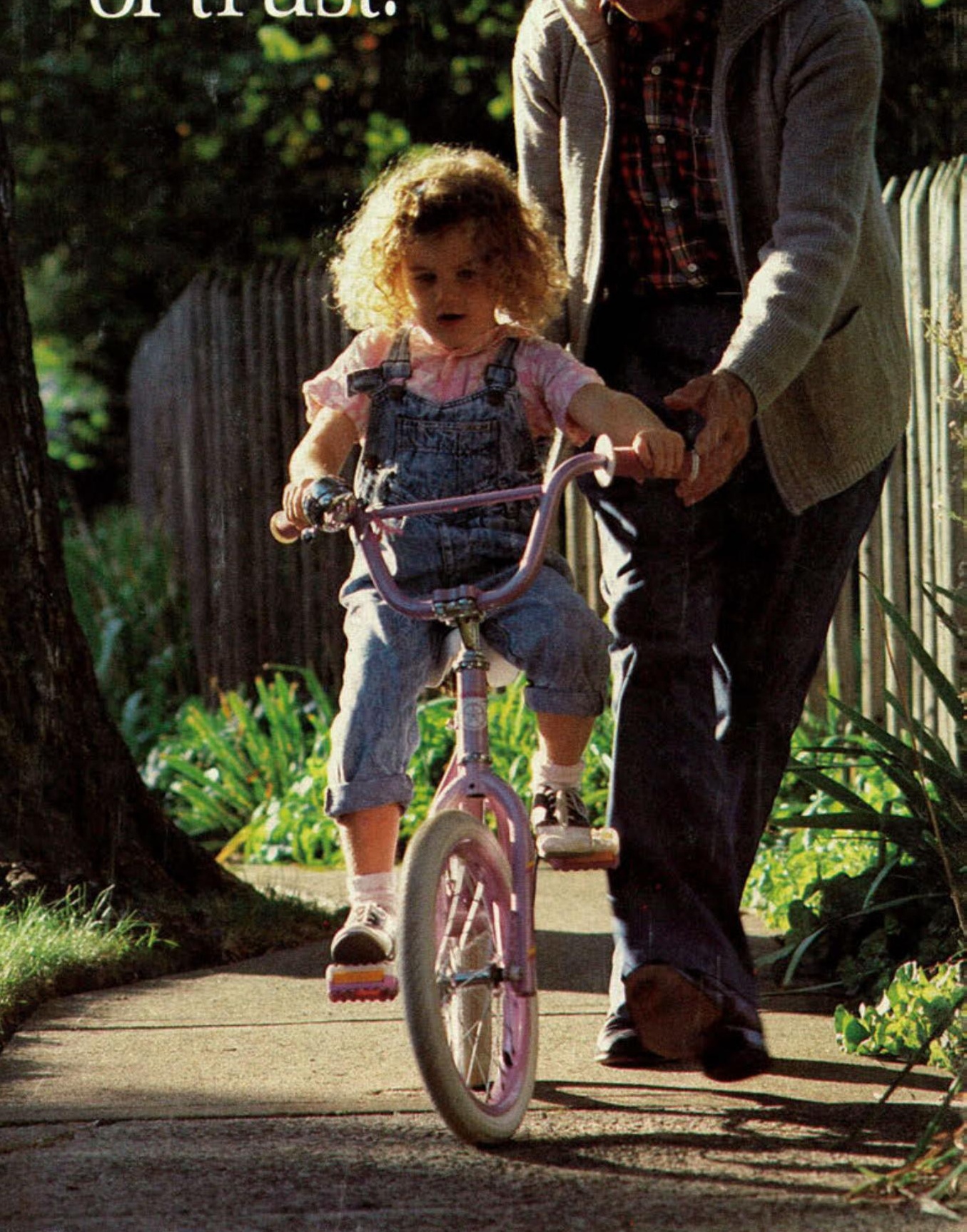

\section{DYAZIDE' The Ouginal}

a product of

SIKEF CO.

Cidra, P.R. 00639

(c) SK\&F Co., 1988 